\title{
ResearchOnline@JCU
}

This is the author-created version of the following work:

Hughes, Terry P., Barnes, Michele L., Bellwood, David R., Cinner, Joshua E., Cumming, Graeme S., Jackson, Jeremy B.C., Kleypas, Joanie, van de Leemput, Ingrid A., Lough, Janice M., Morrison, Tiffany H., Palumbi, Stephen R., van Nes, Egbert H., and Scheffer, Marten (2017) Coral reefs in the Anthropocene. Nature, 546 (7656) pp. 82-90.

Access to this file is available from: https://researchonline.jcu.edu.au/50952/

Please refer to the original source for the final version of this work: 


\section{Coral reefs in the Anthropocene}

Terry P.Hughes ${ }^{1}$, Michele L. Barnes ${ }^{1}$, David R. Bellwood ${ }^{1}$, Joshua E. Cinner ${ }^{1}$, Graeme S. Cumming ${ }^{1}$, Jeremy B. C. Jackson $^{2,3}$, Joanie Kleypas ${ }^{4}$, Ingrid A. van de Leemput ${ }^{5}$, Janice M. Lough ${ }^{1,6}$, Tiffany H. Morrison ${ }^{1}$, Stephen R. Palumbi ${ }^{7}$, Egbert H. van $\mathrm{Nes}^{5}$ \& Marten Scheffer ${ }^{5}$

Coral reefs support immense biodiversity and provide important ecosystem services to many millions of people. Yet reefs are degrading rapidly in response to numerous anthropogenic drivers. In the coming centuries, reefs will run the gaunt-let of climate change, and rising temperatures will transform them into new configurations, unlike anything observed previously by humans. Returning reefs to past configurations is no longer an option. Instead, the global challenge is to steer reefs through the Anthropocene era in a way that maintains their biological functions. Successful navigation of this transition will require radical changes in the science, management and governance of coral reefs.

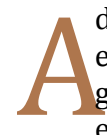
defining feature of the emerging Anthropocene era is the escala- tion of numerous pressures, including climate change, globali- zation and migration, on society and the world's ecosystems ${ }^{1-4}$.

Many coastal coral reefs have already been degraded by centuries of overfishing and pollution, and anthropogenic climate change is exert- ing further stress, even on remote reefs where local pressures are low or absent ${ }^{5-9}$. Increasingly, coral reef scientists and managers encounter previously unseen configurations of species ${ }^{10-12}$. The challenges now are to identify and maintain the ecosystem functions that are crucial for sustaining coral reefs, and to secure the ecosystem services that highly altered reef assemblages can provide to people in the future ${ }^{13}$. Central to this endeavour is an improved understanding of ecosystem functioning and of the types of management and governance that are effective.

In this Review, xxx. First, we examine the implications for coral reefs of a worldwide shift away from business-as-usual emissions of green- house gasses (as agreed at the 2015 United Nations Climate Change Conference(COP21) in Paris) and we re-assess the future threat of global warming and ocean acidification to reef biodiversity. Second, we con- sider whether current experimental evaluations of the impact of rising temperatures and ocean acidification are appropriately calibrated for simulating future conditions. Third, we scrutinize the strengths and weaknesses of conventional scientific approaches to understanding the cumulative, interacting effects of numerous stresses or drivers of change on the trajectories of coral reefs. Fourth, we present a conceptual framework that offers innovative insight into these cumulative impacts and their effects on the complex dynamics of interlinked social and ecological systems. Last, we develop a suite of future options for the governance and management of new and unfamiliar coral reef ecosys- tems. Sustaining reef biodiversity will require a conceptual shift away from the current emphasis on protection, conservation or restoration of stable coral ecosystems at equilibrium, to a reality in which ecosystems are more dynamic and patchier, as well as increasingly different to, anything that 
people have encountered before. Embracing this paradigm shift will necessitate a transformation in the governance and management of these high-diversity ecosystems.

${ }^{1}$ Australian Research Council Centre of Excellence for Coral Reef Studies, J ames Cook University, Townsville 4811, Queensland, Australia. ${ }^{2}$ Scripps Institution of Oceanography, University of California, San Diego, La J olla, California 92093-0244, USA. ${ }^{3}$ Department of Paleobiology, National Museum of Natural History, Smithsonian Institution, Washington DC 20013, USA. ${ }^{4}$ Institute for the Study of Society and Environment, National Center for Atmospheric Research, Boulder, Colorado 80307, USA. ${ }^{5}$ Department of Environmental Sciences, Wageningen University, PO Box 47, 6700 AA Wageningen, the Netherlands. ${ }^{6}$ Australian Institute of Marine Science, PMB 3, Townsville 4810, Queensland, Australia. ${ }^{7}$ Hopkins Marine Station, Department of Biology, Stanford University, Pacific 93950, USA.

\section{Running the climate gauntlet}

The accelerated effort towards global action on climate change calls for a reassessment of the environmental conditions that will test coral reefs in the near future. The goal of the Paris agreement on climate change made at COP 21 is to constrain the increase in global average temperatures "to well below $2{ }^{\circ} \mathrm{C}$ above preindustrial levels and to pursue efforts to limit the temperature increase to $1.5^{\circ} \mathrm{C}$. Consequently, the scenario of $600-1,000$ parts per million (p.p.m.) of atmospheric carbon diox- ide, which underpins most of the scientific literature on the projected impact of rising temperatures and ocean acidification on coral reefs, is no longer realistic - even if the COP 21 agreement is only partially successful ${ }^{14}$. However, it is almost certain that the $1.5^{\circ} \mathrm{C}$ target will not be met for many decades ${ }^{15,16}$. Restraining the rise in global tempera- tures to less than $2^{\circ} \mathrm{C}$ (with a probability of $66 \%$ ) would translate into an atmospheric carbon dioxide concentration of only 410-420 p.p.m. (Fig. 1a) - an amount that is likely to be surpassed in 3-4 years . Fur- thermore, representative concentration pathway (RCP) 2.6, which is the lowest (most optimistic) emissions scenario assessed in the Intergovernmental Panel on Climate Change (IPCC) Fifth Assessment Report, indicates that coral reefs will run a gauntlet of hostile environmental conditions for several centuries, even with a rapid transition to zero emissions ${ }^{17}$. Reefs have already experienced three pan-tropical episodes of intense coral bleaching in the past three decades (1997-1998, 2010 and 2015-2016), triggered by an average global warming of close to $1^{\circ} \mathrm{C}$ above pre-industrial temperatures ${ }^{8,18}$.

The $1.5^{\circ} \mathrm{C}$ and $2{ }^{\circ} \mathrm{C}$ targets, based on global average land and sea temperatures, are misleading metrics for under- standing future changes to coral reefs because of differences in the amounts of warming that land and sea experience ${ }^{19}$, steep latitudinal gradients in temperature and regional discrepancies in rates of warm- ing ${ }^{8}$. The global average temperature of about $14^{\circ} \mathrm{C}$ has lit-tle relevance for tropical sea surface temperatures, which in summer are typically $27-30{ }^{\circ} \mathrm{C}$, or higher. On the basis of the HadCRUT4 global temperature data set $^{20}$, we calculate that the average tropical sea surface temperature rose by 0.57 ${ }^{\circ} \mathrm{C}$ between 1880 and 2015, which is substan- tially lower than the $0.88{ }^{\circ} \mathrm{C}$ increase in global average temperature for the same period. Furthermore, the observed increase in sea surface temperature in the tropics and subtropics since the late nineteenth century has varied substantially at the regional and local scales, with $71 \%$ of reefs worldwide warming by $0.25-0.75{ }^{\circ} \mathrm{C}$, so far (Fig. 1b). This spatial heterogeneity suggests that there is no single 'safe' level, or planetary boundary', of global emissions for all coral reefs. Future increases in temperature will also vary greatly in space and time, which highlights the need for improved regional-scale modelling that incorporates moreoptimistic trajectories of emission reduction.

Future sea surface temperatures under the IPCC's RCP2.6 scenario are projected to increase in the short-term (20102039) in all major coral reef provinces, even as global emissions peak and begin to fall. Further warming projections for this period range from $0.32^{\circ} \mathrm{C}$ in the eastern Indian Ocean to $0.48^{\circ} \mathrm{C}$ in the Caribbean ${ }^{21}$. From 2039 to 2099 , as temperatures begin to stabilize, sea surface temperatures are pro-jected to change further by $+0.20{ }^{\circ} \mathrm{C}$ to $-0.05{ }^{\circ} \mathrm{C}$ across all reef provinces. Consequently, the longer-term warming trend, from 2010 to the end of the twenty-first century, under this low-emissions scenario variesfrom

$0.30{ }^{\circ} \mathrm{C}$ to $0.68{ }^{\circ} \mathrm{C}$ between reef provinces, an increase that is roughly equivalent to the warming observed so far over the past century.

Even if the $2{ }^{\circ} \mathrm{C}$ target of the Paris agreement is achieved, this projected level of warming will still have severe consequences for coral reefs - particularly when temperatures spike above the long-term sum- mer maxima, leading to recurrent bleaching 
events ${ }^{22}$. However, our knowledge of the chronic impacts of up to $1{ }^{\circ} \mathrm{C}$ of further warming on the physiology and demography of reef organisms is surprisingly limited because the range of thermal treatments used most commonly in recent experiments is too high. Typically, these studies apply one or more treatments of elevated water temperatures, for periods that last from a day to a year (or sometimes even longer), to simulatelong-term

global warming on coral reefs. So far, the median manipulation of water temperatures above ambient controls represents an increase of $4{ }^{\circ} \mathrm{C}$ (or of almost $5^{\circ} \mathrm{C}$ above the pre-industrial baseline temperature), and no study has experimentally examined the plausible biological responses to increases in the range of $0.30-0.68^{\circ} \mathrm{C}$ that are projected for various coral reef regions by RCP2.6 (Fig. 1c). Most manipulations also greatly exceed the spikes of $1-3^{\circ} \mathrm{C}$ above baseline summer maximum temperatures that cause coral bleaching.

Similarly, shallow-water $\mathrm{pH}$ and the saturation state of aragonite, a form of calcium carbonate, which are crucial for calcification and other pro- cesses on coral reefs ${ }^{23}$, are likely to change much less than the extremes that are predicted under higher-emission scenarios. The global aver- age $\mathrm{pH}$ of ocean surface waters has declined in the last 200 years by about 0.1 units, from $\mathrm{pH} 8.21$ to $\mathrm{pH} 8.10$ (ref. 24). A further decrease of 0.3-0.4 units (to $\mathrm{pH} 7.7-7.8$ ) would occur if atmospheric carbon diox- ide concentrations reached 800 p.p.m., causing a contraction towards the Equator of optimal conditions for calcification ${ }^{25}$. However, according to more recent modelling by the IPCC ${ }^{21}$, an equilibrium atmospheric concentration of 450 p.p.m. of carbon dioxide would maintain a pH of 7.9-8.1 in most tropical oceanic waters, maintaining a strongly supersaturated aragonite state throughout the tropics and the subtropics. So far, we find no evidence that the geographic range of calcifying species is contracting towards the Equator owing to ocean acidification. On the contrary, as temperatures rise, many species are expanding towards the north and south into the subtropics, despite small decreases in aragonite concentration ${ }^{26,27}$.

Most experiments that are designed to explore the effects of ocean acidification oncoralsandother reeforganisms have simulated extreme levels of atmospheric carbon dioxidethat are designed to match condi- tions predicted for the end of the twenty-first century under uncon- strained emissions of greenhouse gasses (Fig. 1d). Typically, such experiments comprise a control, which corresponds to the present-day atmospheric carbon dioxide concentration of around 400 p.p.m., and oneormoretreatments thatmanipulatepHorwaterchemistry. Abroad range of physiological and demographic responses of coral have been measured, including rates of calcification, growth, reproduction and survival. In 336 manipulations from a sample of 137 published studies, we found none that specifically simulated a future $p \mathrm{CO}_{2}$ of 400-500 p.p.m., the range that reefs are likely to experience for at least the next century. The lowest concentrations, which account for $32.7 \%$ of manipulations, ranged from 500 to 750 p.p.m. (Fig.1d). Consequently, our knowledge of the effects of ocean acidifica- tion under conditions of less than 500 p.p.m. of carbon dioxide is built on the basis of interpolation between ambient controls and unrealisti- cally high experimental treatments. Of the remaining manipulations, 33.9\% studied concentrations of 750-1,000 p.p.m., and 33.3\% evaluated concentrations that were even higher (Fig. 1c) - simulating atmos- pheric conditions that would generate temperatures of $+6^{\circ} \mathrm{C}$ or more that are lethal to corals (Fig. 1a). A similar challenge arises forfield studies of ocean acidification thatuse naturally occurringloca- tions with consistently low $\mathrm{pH}$, includingvolcanic vents or submarine springs, as a proxy for future climatic conditions. The water chemistry typically mimics an atmospheric $p \mathrm{CO}_{2}$ of more than 1,000 p.p.m., but it is necessarily mismatched with current temperatures rather than those predicted for future global warming. Corals have already been affected by recur-rent episodes of mass bleaching and mortality following exposure to warming of only $1-2{ }^{\circ} \mathrm{C}$ above baseline summer maximum tempera- tures for periods of $4-8$ weeks ${ }^{8,18}$. 
Consequently, coral reefs already need to cope with severe global warming whereas they may never encoun- ter the projected physiological and ecological impacts of severe ocean acidification that are simulated in the experimental literature (Fig. 1d). Clearly, ouranalysis (Fig. 1c, d) points to an urgentneed to recalibrate bothtemperatureand ocean-acidification experiments to better under- stand their interactive impact on coral reefs under less-extreme condi- tions. On the basis of a statistical analysis of 25 experiments, the rate of calcification by corals declines on average by $15 \%$ per unit decrease

in the aragonite saturation state ( $\Omega \arg$ ), over the range of $2-4 \Omega^{28}$. However, $p \mathrm{CO}_{2}$ would have to double from 400 to 800 p.p.m. to reduce the present average aragonite saturation state of tropical surface waters 25 (currently $3.01 \Omega_{\text {arg }}$ ) by one unit. There is insufficient experimental evidence to accurately estimate how calcification would decline in response to a more modest emissions trajectory that peaks well below 800 p.p.m. However, interpolation of the available experimental evi- dence suggests that an average decrease in calcification of less than $10 \%$ is likely to occur with an increase in atmospheric carbon dioxide of up to 500-550 p.p.m. Although highly speculative, in the short-term, ris- ing average temperatures could promote coral growth and compensate partially for long-term shifts in aragonite concentrations ${ }^{29}$. For exam- ple, on the most southerly subtropical coast of Western Australia, the calcification rate of corals from the genus Porites increased by $23.5 \%$ between 1900 and 2010, as temperatures rose by $0.10^{\circ} \mathrm{C}$ per decade ${ }^{29}$.

To resolve this uncertainty, there is an urgent need for future experi- ments to examine the synergy between warming and ocean acidifica- tion. This could be achieved by manipulating temperature and water chemistry incrementally, and by matching them to each other, over a more realistic range of projected levels of atmospheric carbon dioxide (400-500 p.p.m.). Recalibrating experimental approaches to global warming and ocean acidification will be challenging because smaller manipulations in temperature and water chemistry are more difficult to regulate, and the resulting biological responses will be harder to detect and quantify.

Although a modest level of oceanic acidification undoubtedly will have discernable effects, mass bleaching events owing to global warming, pollution and overfishing will likely remain the most pressing challenges for reef biodiversity throughout the twenty-first century, ${ }^{73,30,31}$. We can therefore anticipate a rapid expansion of the geographicrange of corals into higher latitudes ${ }^{26,27}$, as well as continued shifts in species composition in response to differences in susceptibility to climate change and other anthropogenic drivers ${ }^{18,32}$. The challenge worldwide is to steer reefs through this period of continued warming, a fundamentally differentmindset to the current focus on managing to maintain the status quo of coral reefs.

\section{Understanding social-ecological dynamics}

In an era of rapid environmental shifts, social change and unprec- edented economic development, the need for improved stewardship of natural systems worldwide has never been greater or more urgent ${ }^{2}$. There is a growing awareness of the considerable influence of people on the functioning of all ecosystems ${ }^{30,33-35}$, as well as a renewed evaluation of the dependence of human society on nature for food security, water, aesthetic values and other ecosystem services (Fig. 2). Securing biodi- versity and ecosystems for future generations requires new governance frameworks, or transformational changes to existing ones, and fresh approaches to ecosystem management. This task is probably greatest in the tropics, where the juxtaposition of billions of people with iconic hotspots of biodiversity presents an unprecedented challenge for secur- ing both human development and conservation outcomes. Yet, until recently ecolo- gists have often ignored human behaviour as the ultimate (or distal) driver of environmental change, focusing instead on more proximal, smaller-scale drivers of change. For example, in the coral reef literature, the grazing rate of herbivorous fishes is often considered to be an impor- tant driver of regime shifts from corals to macroalgae ${ }^{31,36}$. However, grazing by herbivorous fishes is diminished by pressure from fishing, which is itself mediated by more distal social drivers such as poverty or 
market demands ${ }^{30,37}$. Locally, the consumption of reef fish is shaped by a combination of the size, socio-economic status and cultural norms of the human population ${ }^{38}$. By emphasizing proximal drivers rather than more distal human ones, we often inadvertently simplify and re-scale a complex social-ecological problem into a subsystem that is entirely biological, which can distract from the underlying causes and ways to address them.

A social-ecological approach for sustaining ecosystems is beginning to emerge that explicitly links the resilience of ecosystems to governance structures, economies and society ${ }^{2,39-41}$. Social-ecological models of various types havealready been developed for a number of contexts, includingforestry ${ }^{42}$, freshwaterlakes ${ }^{43}$, fisheries ${ }^{44}$ and agriculturalaban- donment ${ }^{45}$. Combining human social systems and ecosystems in the same models reveals further complexity and a richer range of dynam- ics, which presents new possibilities for sustainable solutions (Box 1).

Death by a thousand cuts

Although climate change now dominates the discussion, it is clearly not the only threat in the Anthropocene to the biodiversity, ecological functions and ecosystem services of coral reefs ${ }^{7,13,30,31}$. Approaches to understanding multicausality in coral reef science often categorize the effects of pairs of drivers as being additive, antagonistic or synergistic. For example, if climate change has effect $x$ on the abundance of corals on a reef and overfishing has effect $y$, then climate change and overfish- ing together may, in theory, have an effect that is $x+y$, less than $x+y$ or greater than $x+y^{46}$. In reality, however, the world is not so simple. Both the science and governance of coral reefs are in great need of stronger conceptual and methodological frameworks for understanding and managing multiple drivers and their combined impact.

Currently, the literature on multiple drivers and their impact on coral reefs focuses on three main strands: short-term laboratory or field experiments that manipulate two, or rarely three, stressors (for example, temperature and $\mathrm{pH})^{28}$; statistical analyses that correlate the condition of reefs (for example, coral cover or fish biomass) at several locations or times with a number of factors ${ }^{47,48}$; and global ecological assessments made on the basis of multi-layered geographic informa- tion systems maps (for example, ocean-health maps or Reefs at Risk maps) ${ }^{49,50}$. Each strand can provide valuable insights, but all have con- siderable limitations. For example, experiments that manipulate drivers provide an in-depth understanding at only very small scales (from days to months, and usually in the laboratory) and are therefore unable to examine spatial dynamics or long-term interactions between species. Similarly, multiple regression analyses are often confounded by col- linearity between explanatoryvariables. A tacit assumption in many such analyses, that the current condition of reefs can be explained by the mix and strength of present-day drivers, discounts the role of time lags and past events in shaping the biodiversity trajectories of reefs in a non-equilibrium state ${ }^{51}$. Similarly, global maps portray relative risks at large spatial scales, but they make the unrealistic assumption that stressors are only additive.

Analyses of interacting drivers and multicausality have undergone more extensive development in terrestrial ecology, and their appli- cation has improved both the monitoring and management of eco- systems. For example, in savannas, an indepth understanding of the interaction between fire, herbivory, predation, rainfall and vegetation has been central to developing strategies for the sustainable manage- ment oflarge herbivores ${ }^{52}$. Others studies have proposed the formal use of a process of triangulation that compares and contrasts explorations of models, field studies and laboratory experiments ${ }^{53}$ to cross-validate theories of causality. This builds on the idea that a rigorous understand- ing of multicausality arises from testing hypotheses from a variety of perspectives.

Arguably, current thinking on the responses of ecosystems to one or more drivers is too linear. The ecological response to even a sin- gle stressor is often curved owing to positive or reinforcing feedbacks; small levels of drivers have no impact (for 
example, when pollution is too dilute or heat stress falls below a threshold) but higher amounts increasingly cause an ecological response ${ }^{54}$. Thirty types of positive feed- back have already been observed on coral reefs ${ }^{55}$. Some are ecological or social and others are both. For example, when fish stocks decline, fishers without access to an alternative livelihood often increase their efforts and further suppress the stocks. A strong feedback produces a threshold response, and an even stronger one can cause hysteresis and precipitate a catastrophic collapse $^{54,56}$. When several weak feedbacks act simultaneously, they can collectively promote an unexpected regime shift as the effects of multiple drivers gradually increase ${ }^{55}$.

An area that holds promise for understanding the role of multiple drivers and feedbacks in environmental change is the development of heuristic models. For example, when three drivers (climate change, overfishing and pollution) are modelled simultaneously (Fig. 3), their combined effects become more evident, which first results in transitions from a coral state to alternative states, in which both coral states and non-coral states can occur, and ultimately leads to conditions in which only a macroalgal state is possible. Consequently, the model identifies the concept of a generic 'safe operating space' for coral reefs ${ }^{2,4}$, in which corals are dominant so long as multiple drivers are held below thresholds for coral survival that arise from their combined effects. This result is particularly relevant to the widespread emergence of new driv- ers that affect ecosystems and add to the impact of pre-existing stress- ors, which themselves are likely to strengthen with time. For example, climate change and new coastal developments are adding to the now century-old pressures of overfishing and pollution on marine ecosys- tems. Here, modelling supports the proposal that local action to protect reefs from overfishing and pollution can boost the capacity of reef eco- systems to survive climate change $e^{5,7,10,48,57}$. Therefore, the potential for making changes to social and ecological drivers and feedbacks is crucial when considering avenues for improved governance. Furthermore, the modelled result (Fig. 3) indicates that synergistic human impacts can reduce resilience and cause unexpected ecological collapse, even when individual drivers or stressors remain at levels that are considered to be safe.

\section{Embracing change}

The dynamics of coral reefs in the Anthropocene are already dominated by complex interactions between multiple anthropogenic drivers, which is resulting in new assemblages of species ${ }^{10,31,36}$. Increasingly, we face a fundamentally different reality: it is no longer possible to restore coral reefs to their past configurations. For example, reefs in the Caribbean will never resemble the faunal composition of past centuries, owing to the ecological extinction of megafauna, the massive decline of the once-dominant branching corals of the genus Acropora, the irreversible introduction of the predatory lionfish (Pterois volitans) and the ongo- ing impact of coastal development, overfishing and climate change ${ }^{7,58}$. Similarly, following a massbleaching event and unprecedented mor- tality in 2016, the corals of the remote northern Great Barrier Reef in Australia are unlikely to have sufficient time to fully recover their for- mer species composition before further major bleaching events occur ${ }^{18}$. Instead of attempting to maintain or restore historical baseline assem- blages, the governance and management of coral reefs will need to adapt continuously to the new conditions of the coming centuries.

\section{Biodiversity in a changing world}

In recent years, theoretical and empirical studies have provided a robust framework for understanding the relationship between biodiversityand ecosystem functioning ${ }^{59}$. Itis also now recognized widely that the mor- phologic, demographic and life-history traits of species play a central partin defining ecosystem functioning ${ }^{60}$ and that biodiversity is more than just counts of species; it also includes genetic, phylogenetic and functional diversity ${ }^{59,61-63}$. However, considerable gaps in our knowl- edge remain - in particular, how ecosystem functions will respond to changing compositions of species that are the result of climate change and other anthropogenic drivers. 
Despite their exceptionally high biodiversity, coral reefs are vulner- able to the loss of functionally importantspecies ${ }^{30,62,63}$. For example,reefs support more than 6,000 species of fish, yet crucial functions are often delivered by just a handful of species. A global analysis of unique trait combinations of fish showed that about one-third of functional groups consist of only one species ${ }^{62}$. The proportion offunctionalgroups ofreef fishes that are depauperate is consistent regardless of regional species richness, which suggests that hotspots of high diversity on coral reefs

are just as vulnerable as isolated reefs with low diversity. Consequently, it is becoming clear that biodiversity per seis less important than the functional composition of reefs ${ }^{13,59,64}$, and examples of this are found in the provision of a 3D habitat by branching corals, the control of mac- roalgae by herbivores and the breakdown of dead corals by bioeroders. Identifying and targeting the functions that are required to maintain reef ecosystems offers an opportunity for fresh approaches to both the management and restoration of reefs.

\section{Solution spaces}

For coral reefs to survive and remain functional into the next century and beyond, we need to govern and manage them more effectively. Building on the emerging understanding of nonlinear responses, feed- backs and threshold dynamics in social-ecological systems (Box 1), we propose three complementary approaches to this endeavour.

First, a greater focus on reducing important drivers of change could helptoavoid crossing thresholds that lead to environmental degradation (Fig. 4a). Conversely, drivers that accelerate social change towards more sustainable practices ${ }^{65}$ could be increased. The identification of how severaldriversinteract(for example, those shown in Fig. 3) is crucial for effective intervention.Currentapproachestoreefconservation, includ- ing marine reserves, often seek to limit fishing in selected areas but rarely address the distal causes of fishery overexploitation such as pov- erty and access to markets ${ }^{47}$ (Fig. 2). Understanding and tracking distal social drivers may provide an early warning of unsustainable impacts on reefs before they are detected by ecological indicators ${ }^{37}$. The coupling of modern approaches to reef conservation with sustainable-development initiatives that target distal drivers (for example, by reducing poverty or encouraging shifts in cultural norms such as $\mathrm{xxx}$ ) can produce both positive social ${ }^{66}$ and ecological ${ }^{67}$ outcomes.

Second, there could be opportunities to manipulate ecological thresh- olds so that stronger drivers are required to induce a regime shift or to cause unacceptable levels of degradation (Fig. 4b). This strategy seeks ways to ensure that a particular level of a driver such as pressure from fishing or climate change has less of an impact. Examples include: the introduction of technological innovations such as changes in fishing gear to reduce environmental damage ${ }^{68}$; the fostering of social norms (the informal rules that shape people's attitudes and behaviours) to reduce harmful practices $s^{65,69}$ and to encourage voluntary compliance with environmental laws and regulations ${ }^{70}$; investment in institutions and processes that help to buffer the deleterious effects that social driv- ers such as population size, consumption and access to markets have on cooperation and collective action ${ }^{71}$; and altering the composition of ecosystems to increase the proportion of species that are more tolerant of escalating drivers (for example, heat-tolerant species that bleach and die at higher temperatures or species that recover faster). Ecosystem composition change is already occurring naturally, as corals respond and adapt to climate change (Box 2), and could be promoted further through efforts to actively manipulate ecosystem configurations. In social systems, shifts in the composition of society - for example, through enhanced education or a reduction in poverty - can also increase resilience to strong drivers such as climate change ${ }^{72}$.

Last, feedbacks could be actively altered to flatten the slope of the response curve (Fig. 4c), therefore reducing the risk of transgressing an unknown threshold or eliminating the threshold altogether. This approach could involve weakening positive feedbacks that result in a shift away from a coraldominated state ${ }^{10,31,55,56}$. Examples include pro- viding government-backed incentives for fishers to exit a fishery when 
stocks decline or breaking the poverty-trap dynamics that encourage fishing despite low yields in an overexploited system $^{38,69}$. Understand- ing and manipulating feedbacks, thresholds and drivers at a number of scales will be integral to addressing the escalating problems that con- front coral reefs.

\section{Opportunities for action}

Helping coral reefs to safely navigate the Anthropocene is a profound

challenge for multiscale governance ${ }^{73}$. (In this context, reef governance refers to the myriad ways in which societies share knowledgeand power, createpolicies, build legal frameworks and make decisions. By compari- son, the management of coral reefs is the day-to-day business of reef protection, which is enabled by effective governance.) At present, both the governance and management of coral reefs are typically focused at the local level and on the regulation of proximal drivers (for example, pressure from fishing or nearby coastal development). Attention to dis- tal drivers, including migration, population growth or demand from global markets, is often limited, fragmented and ineffective ${ }^{38}$. But in the Anthropocene, progression from local management and monitoring towards the multiscale governance of drivers, thresholds and feedbacks at relevant scales will be critically important. Here, we identify a number of potential opportunities for overcoming this challenge for governance, many of which fall outside the comfort zone of reef scien- tists and managers.

\section{Redefining management goals}

As reefs continue to reconfigure and decline in the near future, it will be essential to reconsider management and conservation goals and how they can be achieved. Conventional management goals often focus on biodiversity, threatened species or the biomass of fish. Maintaining the ecological functions and ecosystem services of reefs, even as the spe- cies composition of the recent past becomes unattainable, will require a new focus that both builds on the current ecosystem-based model of management ${ }^{74-76}$ and recognizes more explicitly that ecosystems, and the people who depend on them, are changing rapidly. The emerging resiliencebased approach whereby $\mathrm{xxx}$ is a step forward because it acknowledges the importance of ecological processes and the role of human drivers ${ }^{10,31,39,77,78}$. In practical terms, processbased reef man- agement could include reduction of corallivory (coral eating) by the targeted culling of corallivores), enhancement of herbivory through the regulation of specific fisheries, or management of the connectivity of harvested functional groups by enhancing spillover from protected areas. A focus on processes, ecological functions, ecosystem services and human drivers therefore opens many more possibilities for active managementinterventions.

\section{Manipulatingecosystems}

A radical step, which is yet to be widely applied to coral reefs, entails a shift from passive ecosystem management to active ecosystem inter- vention ${ }^{54,79}$. Conventionally, the management of coral reefs has been mostly passive, relying on an implicit assumption that if reefs are pro- tected from human impacts, they will return to their original condition following a disturbance. In the Anthropocene, however, this funda- mental assumption is void, and management and governance frame- works need to specifically embrace changes in the species composition of ecosystems or they will fail. So far, attempts at active intervention such as propagating coral fragments, assisted migration and selective breeding ${ }^{80,81}$ have had limited success and are prohibitively expensive at meaningful spatial scales ${ }^{82}$. For example, the US National Marine Fisheries Service estimates that a recovery plan for two species of the coral Acroporain the Caribbean territories of the United States would cost a minimum of US\$255 million and take more than 400 years to implement ${ }^{83}$. Therefore, finding scalable, enduring and cost-effective interventions is an important and urgent research challenge. Efforts havetypically focused on restoring populations of depleted species such as turtles or targeted corals, often without adequately addressing the drivers that caused their decline in the first place. A broader approach that seeks to reduce multiple pressures and repair key processes, includ- ing herbivory and 
recruitment, remains mostly unexplored.

Building institutions for governance

Multiscale governance is often fragmented and ineffective, and is chal- lenged by issues of jurisdiction and legitimacy, complexity, scale and funding ${ }^{84-86}$. More-effective institutions for global governance could

facilitate the reduction of important drivers (for example, the burning offossilfuels or the trade in functionally important species) byassessing the scientific evidence, setting an agenda for action, managing compli- ance, building capacity and influencing the norms of behaviour. Previ- ous worldwide and transnational successes, includingefforts to address ozone depletion and acid rain, demonstrate that it is feasible to meet the challenge of tackling global issues such as climate change ${ }^{65}$. Further development of international agencies for the global stewardship of threatened ecosystems such as coral reefs could also expedite decision- making and action at national and local levels 87,88 .

\section{Fostering innovative partnerships}

Local, national and transnational partnerships that involve civil soci- ety, development organizations and businesses can complementmore formal governance organizations $^{71,89}$. For example, the Coral Triangle Initiative on Coral Reefs, Fisheries and Food Security is a partnership of three major environmental nongovernment organizations (Conser- vation International, the World Wide Fund for Nature and The Nature Conservancy) and six national governments (Indonesia, Malaysia, Papua New Guinea, the Philippines, the Solomon Islands and Timor- Leste), which is aiming to achieve food security, sustainable fisheries and coral reef conservation at a regional scale $^{67}$.Atthe local scale, partner- ships that build new alliances can also open up avenues for improving the governance and management of reefs, even in the absence of formal nationalgovernance ${ }^{66,73}$.

\section{Changing social norms}

Governments, non-governmental organizations and social movements can actively encourage changes in social norms that lead to improved environmental behaviours ${ }^{65,90}$. These changes can be promoted, for instance, through taxes, incentives, education and communication strategies ${ }^{91}$. Examples include communicating the risks and costs of environmental loss, education programmes that promote the value of marine parks and no-fishing zones, and providing subsidies to support the transition from fossil fuels to renewable energy.

\section{The future for coral reefs}

Confronting the global coral reef crisis will require immediate action to address the emission of greenhouse gasses, as well as a clearer under- standing of multiple drivers and ecosystem responses in the context of new, more realistic, scenarios of global climate change. We need to improve our grasp of the trajectories of interacting drivers and the responses of coral reefs to probable scenarios of temperature and ocean $\mathrm{pH}$. We should also incorporate the social sciences into our understanding of the dynamics of linked socialecological systems. Drivers are becoming stronger and more diverse, as well as shifting in scale from local to global. Through globalization, coral reefs are becom- ing more accessible, which creates a variety of incentives for their exploi- tation but also has the potential to offers new solutions on the basis of multiscale governance, including international actions and policies. The challenge for the future is to steer away from the tipping points that are already manifesting at local scales ${ }^{13,92}$. Future coral reef science should be re-oriented to test the effectiveness of policy and management solutions, to measure the 
success and failure of governance approaches and to modify them accordingly, and to guide the development of new policies ${ }^{93}$.

We should not give up hope for the recovery of Earth's coral reefs. Importantly, governance approaches will need to integrate knowledge of human psychology and risk perception in ways that convey the seri- ousness of the challenges without generating hopelessness or despair. Progressin coral reef governance will require effective, multilevel institutions to coordinate and support action across multiple scales. Action to rein in distal drivers is needed at the global scale, yet there are few central authorities that operate effectively at such a scale ${ }^{84}$. The Paris agreementis already reframingthe possible futures of Earth's coral reefs and the science that underpins their management. To steer coral reefs

through the next century, we will need to be bold, to embrace change and to recognize that securing essential services from coral reefs will requirea new approach to science, management and governance.

Received 10 January; accepted 6 April 2017.

Supplementary Information is linked to the online version of the paper at go.nature.com $/ x x x x x x$.

1. Crutzen, P.J. in Earth System Science in the Anthropocene (eds Ehlers, E. \& Krafft, T.) 13-18 (Springer, 2006).

2. Rockström, J. et al. Planetary boundaries: exploring the safe operating space for humanity. Nature 461, 472-475 (2009).

This groundbreaking study places human impacts on the environment in a global framework and provides a fresh understanding of social-ecological systems.

3. Waters, C. N. et al. The Anthropocene is functionally and stratigraphically distinct from the Holocene. Science 351, aad2622 (2016).

4. Scheffer, M. et al. Creating a safe operating space for iconic ecosystems. Science 347, 1317-1319(2015)

5. Hughes, T. P. et al. Climate change, human impacts, and the resilience of coral reefs. Science 301, 929-933 (2003).

6. Pandolfi, J. M. et al. Global trajectories of the long-term decline of coral reef ecosystems. Science 301, 955-958 (2003).

7. Jackson, J. B. C., Donovan, M. K., Cramer, K. L. \& Lam, V. Status and Trends of Caribbean Coral Reefs: 1970-2012 (Global Coral Reef Monitoring Network, 2014).

8. Heron, S. F., Maynard, J. A., van Hooidonk, R. \&Eakin, C. M. Warming trends and bleaching stress of the world's coral reefs 1985-2012. Sci. Rep. 6, 38402 (2016).

9. Hoegh-Guldberg, O. et al. Coral reefs under rapid climate change and ocean acidification. Science 318, 1737-1742 (2007).

Afoundational paperthatidentifies bothincreases intemperatureandocean acidification as future threats to coral reefs.

10. Hughes, T. P., Graham, N. A. J., J ackson, J . B. C., Mumby, P.J . \& Steneck, R. S. Rising to the challenge of sustaining coral reef resilience. Trends Ecol. Evol. 25, 633-642 (2010).

11. Pandolfi, J. M., Connolly, S. R., Marshall, D. J \& \&Cohen, A. L. Projecting coral reef futures under global warming and ocean acidification. Science 333, 418-422 (2011). This study identifies variable responses of reef corals to temperature increases and ocean acidification, which highlights the potential for alternative future trajectories for coral reefs.

12. Graham, N. A. J., Cinner, J. E., Norström, A. V. \& Nyström, M. Coral reefs as novel ecosystems: embracing new futures. Curr. Opin. Env. Sust. 7, 9-14 (2014).

13. Harborne, A. R., Rogers, A., Bozec, Y.-M. \& Mumby, P. J. Multiple stressors and the functioning of coral reefs. Annu. Rev. Mar. Sci. 9, 445-468 (2017).

14. Rogelj, J . et al. Paris Agreement climate proposals need boost to keep warming well below $2^{\circ} \mathrm{C}$. Nature 534, 631-639 (2016).

A forward-lookingevaluation of thepotential forglobal reductions in the emission of greenhouse gases following the Paris agreement.

15. Rogelj, J et al. Differences between carbon budget estimates unravelled. Nature Clim. Change 6, 245-252 (2016).

16. Mathias, J.-D., Anderies, J. M. \&J anssen, M. A. On our rapidly shrinking capacity to comply with the planetary boundaries on climate change. Sci. Rep. 7, 42061 (2017).

17. Collins, M. et al. in Climate Change 2013: The Physical Science Basis. Contribution of Working Group I to the Fifth Assessment Report of the Intergovernmental Panel on Climate Change (eds Stocker, T. F. et al.) Ch. X, XXX-XXXX (Cambridge Univ. Press, 2013).

18. Hughes, T. P. et al. Global warming and recurrent mass bleaching of corals. Nature 543, 373-377(2017)

19. Sutton, R. T., Dong, B. \& Gregory, J. M. Land/sea warming ratio in response to climate change: IPCC AR4 model results and comparison with observations. Geophys. Res. Lett. 34, L02701 (2007).

20. Morice, C. P., Kennedy, J. J ., Rayner, N. A. \&J ones, P. D. Quantifying uncertainties in global and regional temperature change using an ensemble of observational estimates: the HadCRUT4 data set. J. Geophys. Res. 117, D08101 (2012).

10 | NATURE I PROOF 
21. Hoegh-Guldberg, O. et al. in Climate Change 2014: Impacts, Adaptation, and Vulnerability. Part B: Regional Aspects. Contribution of Working Group /I to the Fifth Assessment Report of the Intergovernmental Panel on Climate Change (eds Barros, V. R. et al.) Ch. 30, 1655-1731 (Cambridge Univ. Press, 2014).

22. Frieler, K. et al. Limiting global warming to $2^{\circ} \mathrm{C}$ is unlikely to save most coral reefs. Nature Clim. Change 3, 165-170 (2013).

23. Author, A. \& Author, B. in Ocean Acidification (eds Gattuso, J.-P. \&Hansson, L.) Ch. X (Oxford Univ. Press, 2011).

24. Rhein, M. et al. in Climate Change 2013: The Physical Science Basis. Contribution of Working Group I to the Fifth Assessment Report of the Intergovernmental Panel on Climate Change (eds Stocker, T. F. et al.) Ch. 3, 255-315 (Cambridge Univ. Press, 2013).

25. Orr, J. et al. Anthropogenic ocean acidification over the twenty-first century and its impact on calcifying organisms. Nature 437, 681-686 (2005).

26. Pandolfi, J. M. Incorporating uncertainty in predicting the future response of coral reefs to climate change. Annu. Rev. Ecol. Evol. Syst. 46, 281-303 (2015).

27. Poloczanska, E. S. et al. Responses of marine organisms to climate change

across oceans. Front. Mar. Sci. 3, 62 (2016).

28. Chan, N. C. S. \& Connolly, S. R. Sensitivity of coral calcification to ocean acidification: a meta-analysis. Glob. Change Biol. 19, 282-290 (2013).

29. Cooper, T. F., O'Leary, R. A. \& Lough, J. M. Growth of Western Australian corals in the Anthropocene. Science 335, 593-596 (2012).

30. Bellwood, D. R., Hoey, A. S. \&Hughes, T. P. Human activity selectively impacts the ecosystem roles of parrotfishes on coral reefs. Proc. R. Soc. B 279, 1621-1629 (2012).

31. Graham, N. A. J . et al. Managing resilience to reverse phase shifts in coral reefs Front. Ecol. Environ. 11, 541-548(2013).

32. Swain, T. D. et al. Coral bleaching response index: a new tool to standardize and compare susceptibility to thermal bleaching Glob. Change Biol. 22, 2475-2488 (2016).

33. Zhang, K., Dearing, J. A., Tong, S. L. \& Hughes, T. P. China's degraded environment enters a new normal. Trends Ecol. Evol. 31, 175-177 (2016)

34. Barnosky, A. D. et al. Merging paleobiology with conservation biology to guide the future of terrestrial ecosystems. Science 355, eaah4787 (2017)

35. Vitousek, P. M., Mooney, H. A., Lubchenco, J. \& Melillo, J. M. Human domination of Earth's ecosystems. Science 277, 494499 (1997).

36. Bellwood, D. R., Hughes, T. P., Folke, C. \& Nyström, M. Confronting the coral reef crisis. Nature 429, 827-833 (2004).

37. Hicks, C. C., Crowder, L. B., Graham, N. A. J., Kittinger, J. N. \& Le Cornu, E. Social drivers forewarn of marine regime shifts. Front. Ecol. Environ. 14, 252-260 (2016).

38. Cinner, J. E. \& Kittinger, J. N. in Ecology of Fishes on Coral Reefs (ed. Mora, C.) 215-220 (Cambridge Univ. Press, 2015).

39. Levin, S. et al. Social-ecological systems as complex adaptive systems: modeling and policy implications. Environ. Dev. Econ. 18, 111-132 (2013).

40. Fischer, J. et al. Advancing sustainability through mainstreaming a social- ecological systems perspective Curr. Opin. Env. Sust. 14, 144-149 (2015).

41. Cumming, G. S., Morrison, T. H. \& Hughes, T. P. New directions for understanding the spatial resilience of social-ecological systems. Ecosystems http://dx.doi.org/10.1007/s10021-0160089-5 (2016)

42. Satake, A. , J anssen, M. A., Levin, S. A. \&I wasa, Y. Synchronized deforestation induced by social learning under uncertainty of forest-use value. Ecol. Econ. 63, 452-462 (2007).

43. Martin, R. \& Schlüter, M. Combining system dynamics and agent-based modeling to analyze social-ecological interactions - an example from modeling restoration of a shallow lake. Front. Environ. Sci. 3, 66 (2015).

44. Laborde, S. et al. Social-ecological feedbacks lead to unsustainable lock-in in an inland fishery. Glob. Environ. Change 41, 13-25 (2016).

45. Figueiredo, J. \& Pereira, H. M. Regime shifts in a socioecological model of farmland abandonment. Landscape Ecol. 26, 737-749 (2011).

46. Ban, S. S., Graham, N. A. J . \& Connolly, S. R. Evidence for multiple stressor interactions and effects on coral reefs. Glob. Change Biol. 20, 681-697 (2014).

47. Cinner, J. E. et al. Bright spots among the world's coral reefs. Nature 535, 416-419(2016)

48. Graham, N. A. J. . Jennings, S., MacNeil, M. A., Mouillot, D. \& Wilson, S. K. Predicting climate-driven regime shifts versus rebound potential in coral reefs. Nature 518, 94-97 (2015)

49. Burke, L., Reytar, K., Spalding, M. \& Perry, A. Reefs at Risk Revisited (World Resources Institute, 2011).

50. Halpern, B. S. et al. Spatial and temporal changes in cumulative human impacts on the world's ocean. Nature Commun. 6, 7615 (2015).

51. Hughes, T. P., Linares, C., Dakos, V., van de Leemput, I. A. \& van Nes, E. H. Living dangerously on borrowed time during slow, unrecognized regime shifts. Trends Ecol. Evol. 28, 149-155 (2013). 
52. Owen-Smith, N. Spatial ecology of large herbivore populations. Ecography 37, 416-430(2014)

53. Plowright, R. K., Sokolow, S. H., Gorman, M. E., Daszak, P.\& Foley, J. E. Causal inference in disease ecology: investigating ecological drivers of disease emergence. Front. Ecol. Environ. 6, 420-429 (2008).

54. Scheffer, M., Carpenter, S., Foley, J. A., Folke, C. \&Walker, B. Catastrophicshifts in ecosystems. Nature 413, 591-596 (2001).

55. van de Leemput, I. A., Hughes, T. P., van Nes, E. H. \& Scheffer, M. Multiple feedbacks and the prevalence of alternate stable states. Coral Reefs 35, 857-865 (2016).

56. Nyström, M. et al. Confronting feedbacks of degraded marine ecosystems. Ecosystems 15, 695-710 (2012).

57. Knowlton, N. \&J ackson, J. B. C. Shifting baselines, local impacts, and global change on coral reefs. PLoS Biol. 6, 215220 (2008).

58. Johnston, M. W. \& Purkis, S. J. Spatial analysis of the invasion of lionfish in the western Atlantic and Caribbean. Mar. Pollut. Bull. 62, 1218-1226 (2011).

59. Cardinale, B. J. et al. Biodiversity loss and its impact on humanity. Nature 486, 59-67 (2012).

This Review provides a scientific consensus on biodiversity, ecosystem functioning and their potential impacts on society.

60. Madin, J. S. et al. A trait-based approach to advance coral reef science. Trends Ecol. Evol. 31, 419-428 (2016).

61. Devictor, V. et al. Defining and measuring ecological specialization. J. Appl. Ecol. 47, 15-25(2010).

62. Mouillot, D. et al. Functional over-redundancy and high functional vulnerability in global fish faunas on tropical reefs. Proc. Natl Acad. Sci. USA 111, 13757- 13762 (2014).

63. Mouillot, D. et al. Rare species support vulnerable functions in high-diversity ecosystems. PLoS Biol. 11, el001569 (2013). This paper highlights the potential vulnerability of high-diversity systems owing to the loss of rare species with functional importance.

64. Naeem, S., Duffy, J. E. \& Zavaleta, E. The functions of biological diversityin an age of extinction. Science 336, 1401-1406 (2012).

65. Nyborg, K. et al. Social norms as solutions. Science 354, 42-43 (2016).

66. Gurney, G. G., Pressey, R. L., Cinner, J. E., Pollnac, R. \& Campbell, S. J. Integrated conservation and development: evaluating a community-based marine protected area project for equality of socioeconomic impacts. Phil. Trans. $R$. Soc. B 370, 20140277 (2015).

67. Christie, P. et al. Improving human and environmental conditions through the Coral Triangle I nitiative: progress and challenges. Curr. Opin. Env. Sust. 19, 169-181 (2016).

68. Johnson, A. E. Reducing bycatch in coral reef trap fisheries: escape gaps as a step towards sustainability. Mar. Ecol. Prog. Ser. 415, 201-209 (2010).

69. Barrett, C. B. \& Constas, M. A. Toward a theory of resilience for international development applications. Proc. Natl Acad. Sci. USA 111, 14625-14630 (2014).

70. Arias, A. Understanding and managing compliance in the nature conservation context. J. Environ. Manage. 153, 134-143 (2015).

71. Ostrom, E. Polycentric systems for coping with collective action and global environmental change. Glob. Environ. Change 20, 550-557 (2010).

72. Brown, K. Resilience, Development and Global Change (Routledge, 2016).

73. Keohane, R. O. The global politics of climate change: challenge for political science. Political Sci. Politics 48, 19-26 (2015).

74. Ruckelshaus, M., Klinger, T., Knowlton, N. \& DeMaster, D. P. Marine ecosystembased management in practice: scientific and governance challenges. Bioscience 58, 53-63 (2008).

75. McCook, L. J. et al. Adaptive management of the Great Barrier Reef: a globally significant demonstration of the benefits of networks of marine reserves. Proc. Natl Acad. Sci. USA 107, 18278-18285 (2010).

76. Lubchenco, J., Cerny-Chipman, E. B., Reimer, J. N. \& Levin, S. A. The right incentives enable ocean sustainability successes and provide hope for the future. Proc. Natl Acad. Sci. USA 113, 14507-14514 (2016).

77. Hughes, T. P., Bellwood, D. R., Folke, C., Steneck, R. S. \&Wilson, J. New paradigms for supporting the resilience of marine ecosystems. Trends Ecol. Evol. 20, 380-386 (2005)

78. Lam, V.Y.Y., Doropoulos, C. \& Mumby, P.J. The influence of resilience-based management on coral reef monitoring: a systematic review. PLOS ONE 12, e0172064 (2017).

79. Hobbs, R. J., Hallett, L. M., Ehrlich, P. R. \& Mooney, H. A. Intervention ecology: applying ecological science in the twenty-first century. Bioscience $61,442-450$ (2011).

80. van Oppen, M. J. H., Oliver, J. K., Putnam, H. M. \& Gates, R. D. Building coral reef resilience through assisted evolution. Proc. Natl Acad. Sci. USA 112, 2307-2313 (2015).

81. Hoegh-Guldberg, O. et al. Assisted colonization and rapid climate change. Science 321, 345-346 (2008).

82. Bayraktarov, E. et al. The cost and feasibility of marine coastal restoration. Ecol. Appl. 26, 1055-1074 (2016).

83. US National Marine Fisheries Service. Recovery plan for elkhorn coral (Acropora palmata) and staghorn coral (A. cervicornis) http://www.nmfs.noaa.gov/pr/ recovery/plans/final acropora recovery plan.pdf (2015).

84. Walker, B. et al. Looming globäl-scale failures and missing institutions. Science 325, 1345-1346 (2009).

85. Keohane, R. O. \& Victor, D. G. The regime complex for climate change. Perspect. Polit. 9, 7-23 (2011).

86. Levin, K., Cashore, B., Bernstein, S. \& Auld, G. Overcoming the tragedy of super wicked problems: constraining our future selves to ameliorate global climate

12 I NATURE | PROOF 
change. Policy Sci. 45, 123-152 (2012).

87. Bai, X. et al. Plausible and desirable futures in the Anthropocene: a new research agenda. Glob. Environ. Change 39, 351-362 (2016).

88. Biermann, F. et al. Navigating the Anthropocene: improving earth system governance. Science 335, 1306-1307 (2012).

A key paper that emphasizes the need for governance approaches to changes that occur in response to human impacts on the environment.

89. Cole, D. H. Advantages of a polycentric approach to climate change policy. Nature Clim. Change 5, 114-118(2015).

90. Young, H. P. The evolution of social norms. Annu. Rev. Econom. 7, 359-387 (2015).

91. Kahneman, D. Thinking, Fast and Slow (Farrar, Straus and Giroux, 2011).

92. Oliver, T. H. et al. Biodiversity and resilience of ecosystem functions. Trends Ecol. Evol. 30, 673-684 (2015).

93. Ferraro, P. J. \& Pressey, R. L. Measuring the difference made by conservation initiatives: protected areas and their environmental and social impacts. Phil. Trans. R. Soc. B 370, 20140270 (2015).

94. Rogelj, J., Meinshausen, M. \& Knutti, R. Global warming under old and new scenarios using IPCC climate sensitivity range estimates. Nature Clim. Change 2, 248-253 (2012).

95. Hartmann, D. et al. in Climate Change 2013: The Physical Science Basis. Contribution of Working Group I to the Fifth Assessment Report of the Intergovernmental Panel on Climate Change (eds Stocker, T. F. et al.) Ch. 2, 159-254 (Cambridge Univ. Press, 2013).

96. Rayner, N. A. et al. Global analyses of sea surface temperature, sea ice, and night marine air temperature since the late nineteenth century. J. Geophys. Res. 108, 4407 (2003).

A foundational study that establishes the main physical characteristics of global climate change.

97. Lough, J. M. Small change, big difference: sea surface temperature distributions

for tropical coral reef ecosystems, 1950-2011. J. Geophys.

Res. 117, C09018 (2012).

98. Palumbi, S. R., Barshis, D. J ., Traylor-Knowles, N. \&Bay, R. A. Mechanisms of reef coral resistance to future climate change. Science 344, 895-898 (2014).

99. Kenkel, C. D. \& Matz, M. V. Gene expression plasticity as a mechanism of coral adaptation to a variable environment. Nature Ecol. Evol. 1, 0014 (2016).

100. Baker, A. C. Reef corals bleach to survive change. Nature 411, 765-766 (2001).

101. Dixon, G. B. et al. Genomic determinants of coral heat tolerance across latitudes. Science 348, 1460-1462 (2015)

102. Howells, E. J., Berkelmans, R., van Oppen, M. J. H., Willis, B. L. \&Bay, L. K. Historical thermal regimes define limits to coral acclimatization. Ecology 94, 1078-1088 (2013).

103. Bay, R. A. \& Palumbi, S. R. Multilocus adaptation associated with heat resistance in reef-building corals. Curr. Biol. 24, 29522956 (2014).

104. Silverstein, R. N., Cunning, R. \& Baker, A. C. Change in algal symbiont communities after bleaching, not prior heat exposure, increases heat tolerance of reef corals. Glob. Change Biol. 21, 236-249 (2015).

105. Munday, P. L., Donelson, J. M. \& Domingos, J. A. Potential for adaptation to climate change in a coral reef fish. Glob. Change Biol. 23, 307-317 (2017).

106. Putnam, H. M., Davidson, J. M. \&Gates, R. D. Ocean acidification influences host DNA methylation and phenotypic plasticity in environmentally susceptible corals. Evol. Appl. 9, 1165-1178 (2016).

107. Ainsworth, T. D. et al. Climate change disables coral bleaching protection on the Great Barrier Reef. Science 352, 338-342 (2016).

Acknowledgements The authors acknowledge the seven institutions that supported this research, in Australia, the Netherlands and the United States. Six of the authors are supported by funding from the Australian Research Council's Centre of Excellence Program. Other funding support includes the Australian Commonwealth Government, the Netherlands Earth System Science Centre (NESSC), the Gordon and Betty Moore Foundation and the US National Science Foundation.

Author Contributions All authors contributed to the development of the paper.

T.P.H. led the initial planning and writing. J.M.L and J.K. undertook

the climate analysis, I.v.d.L, M.S and E.v.N. carried out the modelling; M.L.B., J.E.Cand T.H.Mled the social science component; and D.R.B., G.S.C., T.P.H., J.B.C.J . and S.R.P. provided

the ecological and evolutionary elements.

Author Information Reprints and permissions information is available at www.nature.com/reprints. The authors declare no competing financial interests. Readers are welcome to comment on the online version of this paper at go. nature.com $/ x x x x x x$. Correspondence should be addressed to T.P.H. (terry.hughes@jcu.edu.au).

Reviewer Information Nature thanks T. Gouhier, R. Richmond and the other anonymous reviewer(s) for their contribution to the peer review of this work. 
Figure 1 | The climate gauntlet faced by coral reefs. a, The relationship between stabilized concentrations of atmospheric carbon dioxideand stabilized increases in global average temperature above pre-industrial levels. The dashed line indicates a probability of $66 \%$. Adapted from ref. 94. b, Global trends in tropical sea surface temperature from 1880 to 2015 . Rates of warming of annual average sea surface temperature were calculated on the basis of linear trend analysis of the HadISST data set ${ }^{95,96}$ for all $1^{\circ}$ latitude by $1^{\circ}$ longitude boxes between $30.5^{\circ} \mathrm{N}$ and $30.5^{\circ} \mathrm{S}^{97}$ (the geographic zone in which coral reefs form).c. The range of temperature treatments used to experimentally simulate global warming on coral reef organisms.d, The range of atmospheric concentrations of carbon dioxide that correspond to experimental tests of ocean acidification on coral reefs. The arrows in a, $c$ and dindicate the $2^{\circ} \mathrm{C}$ target (with 66\% probability) set by the 2015 Paris agreement on climate change. (See Supplementary Information Tables 1 and 2 for data used in c and d, respectively.)

Figure 2 | Linkages and feedbacks between people and coral reefs. Distal drivers (blue) are traits in social systems that indirectly influencehow people interactwith coral reefs. Proximate drivers (red) directly affect coral reef ecosystems (centre). Coral reefs provide important ecosystem services to people (pink), which influence aspects of human well-being (green). Single- headed arrows indicate how the pathway flows from distal drivers to human well-being. However, complex linkages and feedbacks also occur between the various components and are shown by the double-headed arrows. Modified from ref. 38 .

Figure 3 The modelled response of coral reefs to multiple anthropogenic drivers. Depending on the strength and interaction between certain anthropogenic drivers (climate change, nutrient pollution and fishing), three outcomes are possible: when the drivers are weak, healthy coraldominated assemblages form (coral state, red); when the driver are strong, a state dominated by macroalgae with few corals forms (green); an intermediate condition in which alternative stable states occur (purple). Interfaces between the coral, alternative and macroalgal states represent the tipping points or thresholds for each combination of drivers. The coral state collapses if the stress from anyonedriver is too strong and is eliminated entirely by the cumulative impacts of multiple drivers. The width and shape of the region of alternative stable states depends on the strength of interacting feedbacks. (See Supplementary Note 1 for further details about the model.)

Figure 4 | A heuristic model of future management options for coral reefs. Future management approaches are modelled on the basis of an improved understanding of the response of ecosystems and human societies to multiple drivers of change. Current pathways from a healthy system to a degraded system are shown as black curves, and the red representsvarious potential approaches to reef management. The relative strength of several drivers could be reduced to move the system away from a dangerous threshold (left). Thresholds could be manipulated to enable the system to handle higher levels of drivers without collapsing (centre). Multiple feedbacks could be managed to change the shape of the equilibrium response curve, which eliminates the risk of surpassing a tipping point (right). 


\section{A framework for modelling social-ecological dynamics}

Models that explicitly include feedbacks and nonlinear interactions within and between social and ecological systems are essential for understanding and analysing their intertwined dynamics. Here, we consider the hypothetical response of fish stocks to the intensity of fishing (Box 1 Fig. a) and vice versa (Box 1 Fig. b). In both cases, and depending on the strength of the feedbacks, a spectrum of responses is possible, ranging from linear to hysteretic. In a coupled social-ecological system, the simplest interaction (Box 1 Fig. c) is represented by two intersecting smooth responses, with a single stable equilibrium at intermediate levels of fishing intensity and stock size.

Depending on the shapes and intersections of the response curves, much more complicated dynamics can arise. When both the ecological and social elements exhibit hysteresis owing to strong feedbacks (Box 1 Fig. d), this can lead to four alternate stable equilibria (I-IV), which are classified according to the level of fish stocks and high fishing intensity. Subtle changes in either the social system or the ecological system can therefore produce profound differences in social-ecological dynamics. The most probable transitions between the four equilibria are directional, moving from II (the best-case scenario of both high fishing intensity and high fish stocks) to IV (fish stocks have collapsed and fishing remains high) then to III (both fish stocks and the fishery are degraded) and to I (fish stocks recover under light fishing). Consequently, the model suggests that the pathway to return to II (the best-case scenario) when the coupled system has collapsed to IV would be for both fish stocks and fishing intensity to decline to III and then shift to I before improving. Effectively, conditions are likely to get worse before they get better. 


\section{The acclimatization and adaptation of corals}

It is becoming clearer that acclimatization and adaptation of corals to rapid changes in climate is already underway. Individual species of coral thrive in a variety of habitats and biogeographic locations because of their capacity to respond to a broad spectrum of temperatures, at both the physiologic and population levels. Field studies using the reciprocal transplantation of coral clones also show that individual colonies have the ability to shift their temperature tolerance ${ }^{98,99}$. These shifts are associated with changes in gene expression, symbiont levels or colony growth pattems. Shifts towards partnerships with more heat-tolerant algal symbionts have also been recorded in individual colonies, especially after bleaching events ${ }^{100}$. However, populations of coral that live in different thermal regimes also show fixed differences in heat tolerance that are not erased by acclimatization ${ }^{98,101}$. Transplants along latitudes on the Great Barrier Reef ${ }^{102}$ or from inshore to offshore populations ${ }^{99}$ show a strong pattern of adaptation to their local thermal profile.

The mechanisms of local adaptation remain unclear. Genome scans and mating studies suggest that heat tolerance is influenced by the action of many genes ${ }^{101,103}$. However, there are other opportunities for the evolution of fixed differences between coral populations besides the influence of classic natural selection on coral genes. Populations of corals in different reef microhabitats often differ in the type of symbiont they acquire at settlement, or following shifts due to heat stress or the differential effects of bleaching ${ }^{104}$. Epigenetic changes through DNA methylation generate heritable changes in gene expression in reef fish ${ }^{105}$ and have also been documented in corals ${ }^{106}$. These mechanisms, and the complex adaptive patterns that they produce, do not lend themselves to simple manipulation through genetic engineering.

Current data strongly show that reef corals exist as a mosaic of populations that respond physiologically to local heat stress in order to lessen damage from high temperatures ${ }^{107}$. Microhabitats that experience periodic extremes of temperature can promote heatresistant corals. Such corals will be crucial for the persistence of coral reefs through the upheavals of the Anthropocene. 